\section{University of New Hampshire}

Carsey School of Public Policy

\section{CARSEY}

National Fact Sheet \#32
RESEARCH

Fall 2015

\title{
Rural Adolescents Are More Likely Than Their Urban Peers to Abuse Prescription Painkillers
}

\section{Shannon M. Monnat and Khary K. Rigg}

U.S. media and popular culture historically portrayed drug abuse as an urban problem, but in recent years, there has been more media attention on rural drug issues. Part of this growing attention pertains to the growing epidemic of narcotic painkiller abuse in rural America. Although all areas of the country experienced increases in painkiller prescribing, abuse, and mortality over the past two decades, the increases have been most pronounced in small towns and rural areas. ${ }^{1}$ This rural drug epidemic requires immediate attention from policy makers and practitioners.

During the 1980s and 1990s, pharmaceutical companies aggressively marketed OxyContin ${ }^{\oplus}$ and other opioids in Appalachia, ${ }^{2}$ and physicians regularly dispensed painkillers to coal miners and other heavy-occupation laborers. ${ }^{3}$ In the 2000s, prescription painkillers became more difficult to obtain in Appalachia due to the introduction of prescription drug monitoring programs and a Drug Enforcement Administration crackdown on "pill mills." Consequently, addicts and dealers from rural Kentucky, West Virginia, Tennessee, and Ohio regularly travelled along what journalists nicknamed the "Oxy Express" to purchase pills in Florida, where prescribing laws were more lax. ${ }^{4}$ Since 2000, prescription painkiller abuse has spread to other rural areas where it was previously uncommon, including New Hampshire and Maine. ${ }^{5}$

Over 1.1 million U.S. adolescents (4.7 percent of youth aged 12-17) abused prescription painkillers in 2014. Among teens, only marijuana and alcohol are more frequently abused than prescription painkillers. Adolescents abuse painkillers more than crack/cocaine, ecstasy, heroin, hallucinogens, inhalants, and methamphetamine combined. Painkiller abuse during adolescence has significant implications for later life. Individuals who abuse painkillers before age 18 are more likely to become addicted than those who first abuse them as adults. Painkiller addiction in youth also increases the likelihood of economic

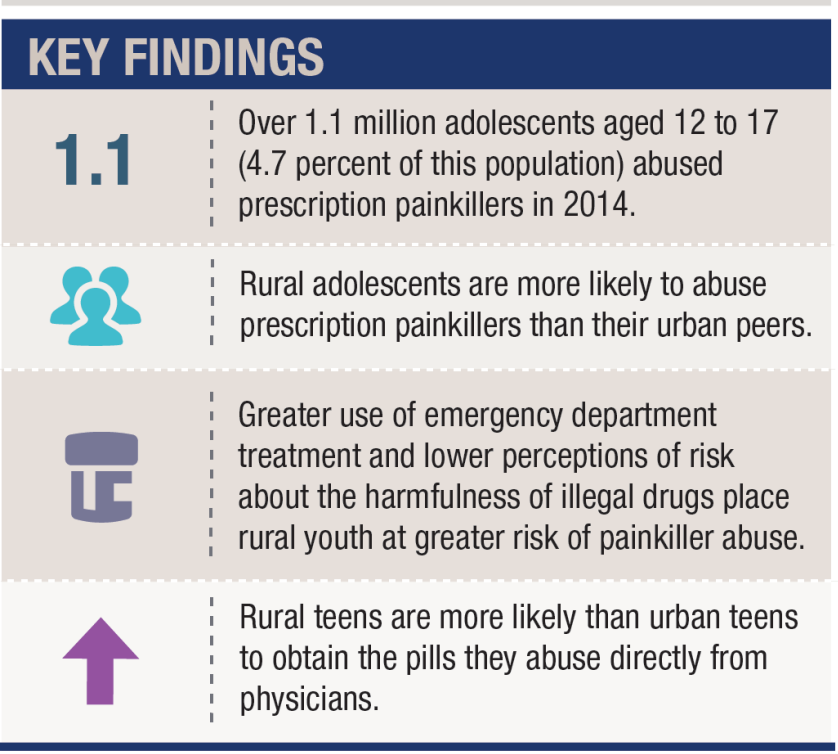

precariousness, criminal justice involvement, poor health, and accidental overdose in adulthood.

\section{The Rural Teen Painkiller Problem}

Prescription painkiller abuse is more common among rural than urban adolescents. In 2014, 8.6 percent of rural adolescents, 8.1 percent of adolescents in small urban areas, and 6.5 percent of adolescents in large urban areas reported ever abusing prescription pain relievers. Past year and past month use were also higher among rural adolescents.

Rural teens' interactions with the health care system increase their risk of painkiller abuse. They are more likely than urban teens to use emergency department (ED) services, where painkillers are more commonly prescribed, and to more frequently visit EDs. Although most teens illicitly acquire painkillers through family or friends (67 percent), rural teens are less likely than urban teens to do so. Rather, they are more likely to obtain the 


\section{FIGURE 1. PERCENT OF ADOLESCENTS REPORTING LIFETIME, PAST YEAR, AND PAST MONTH ABUSE OF PRESCRIPTION PAINKILLERS, 2014}

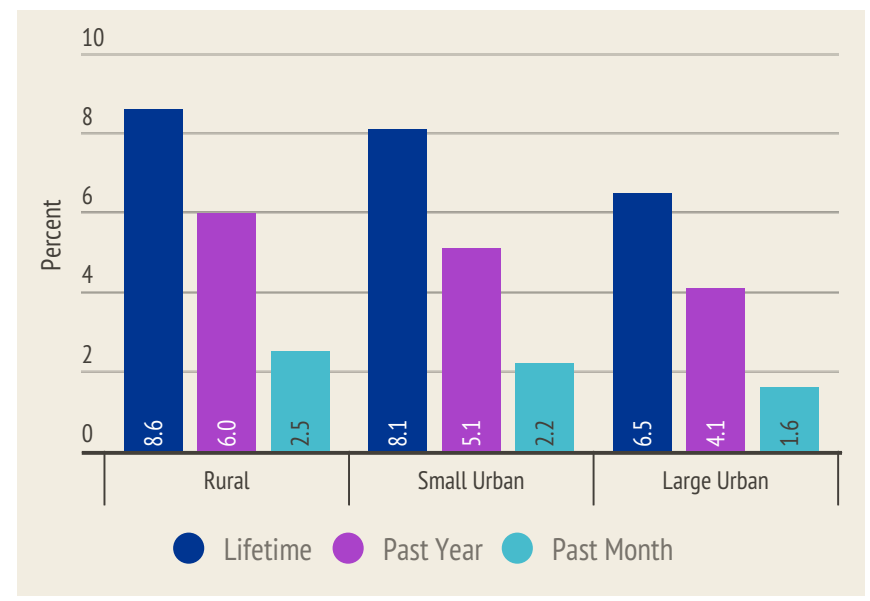

Source: Substance Abuse and Mental Health Services Administration, 2014

pills they abuse directly from physicians (23 percent of rural versus 18 percent of urban). Rural adolescents also perceive substance abuse as less risky than their urban peers. Adolescents with less risky attitudes about substance abuse are more likely to abuse painkillers and other substances. In addition to painkillers, rural teens are also more likely than urban teens to binge drink and smoke cigarettes daily.

Our research shows that some features of rural life do buffer rural teens against painkiller abuse. These include stronger religious beliefs and less peer substance use compared to their urban peers and the geographic isolation that limits access to drugs more than in urban areas. If not for these protective factors, rural teen prescription painkiller abuse would be even higher.

Painkiller abuse is often a pathway to heroin use, particularly when painkillers become too expensive or difficult to acquire. ${ }^{7}$ Recent declines in adolescent prescription painkiller abuse are encouraging, but civic leaders, policy makers, public health experts, and parents should remain vigilant of the risk of adolescents transitioning to heroin. Heroin contains the same active ingredient as prescription painkillers, and heroin is now easier and cheaper for teens to purchase than a pack of cigarettes or a six-pack of beer. ${ }^{8}$ Risk of accidental heroin overdose is especially high because the drug is sometimes tainted with other substances, including fentanyl, which can be lethal even in small doses. Whether today's rural teen painkiller abusers will become tomorrow's rural adult heroin addicts remains an open question. The answer depends on how quickly and resolutely government leaders and public health professionals address the current painkiller problem.

\section{Methods}

We examined prescription painkiller abuse for over 32,000 youth aged $12-17$ using data from the National Survey on Drug Use and Health, an annual nationally representative survey of the non-institutionalized U.S. population. Large urban counties are in metro areas with at least 1 million residents. Small urban counties are in metro areas with under 1 million residents. Rural counties are outside of metropolitan areas.

\section{End notes}

1. K. M. Keyes et al., "Understanding the Rural-Urban Differences in Nonmedical Prescription Opioid Use and Abuse in the United States," American Journal of Public Health, 104:e52-e59 (2014).

2. P. J. Wininger, "Pharmaceutical Overpromotion Liability: The Legal Battle Over Rural Prescription Drug Abuse," Kentucky Law Journal 93(1) (2004): 269.

3. C. G. Leukefeld et al., "What Does the Community Say: Key Informant Perceptions of Rural Prescription Drug Use," Journal of Drug Issues 37(3) (2007): 503-524.

4. Greg Allen, “The 'Oxy Express': Florida's Drug Abuse Epidemic,” NPR Morning Edition, March 2, 2011. http://www. npr.org/2011/03/02/134143813/the-oxy-express-floridas-drugabuse-epidemic.

5. CDC Vital Signs, 2014. "Opioid Painkiller Prescribing: Where You Live Makes a Difference.” http://www.cdc.gov/vitalsigns/ opioid-prescribing/.

6. Substance Abuse and Mental Health Services Administration, 2014. Results from the 2014 National Survey on Drug Use and Health: Detailed Tables. http://www.samhsa.gov/data/sites/default/ files/NSDUH-DetTabs2014/NSDUH-DetTabs2014.pdf.

7. L. E. Grau et al., "Illicit Use of Opioids: Is OxyContin a 'Gateway Drug'?” American Journal of Addiction 16(3) (2007): 166-73.

8. L. Bernstein, "Why a Bag of Heroin Costs Less than a Pack of Cigarettes," The Washington Post, August 27, 2015. https:// www.washingtonpost.com/news/to-your-health/wp/2015/08/27/ why-a-bag-of-heroin-costs-less-than-a-pack-of-cigarettes-2/.

\section{About the Authors}

Shannon M. Monnat is an Assistant Professor of Rural Sociology, Demography, and Sociology and a Research Associate in the Population Research Institute at Pennsylvania State University (smm67@psu.edu).

Khary K. Rigg is an Assistant Professor of Mental Health Law and Policy at University of South Florida and a Research Fellow with the Penn Center for Public Health Initiatives at University of Pennsylvania (rigg@usf.edu).

This report summarizes our research in S. M. Monnat and K. K. Rigg. 2015. "Examining Rural/Urban Differences in Prescription Opioid Misuse among US Adolescents." Journal of Rural Health. http:// onlinelibrary.wiley.com/doi/10.1111/jrh.12141/abstract. Monnat acknowledges support from the Robert Wood Johnson Foundation New Connections Program and the Penn State Population Research Institute, which receives core funding from the National Institute of Child Health and Human Development (Grant R24-HD041025). 